\title{
MENINGITES PURULENTAS EM CRIANÇAS NO PRIMEIRO ANO DE VIDA.
}

\author{
M. VALERIANA L. DE MOURA-RIBEIRO *
}

\begin{abstract}
RESUMO - Foram estudadas 169 crianças com diagnóstico de menlngencefalite purulenta aguda e que manifestaram a doença no primeiro ano de vida. Săo feitas consideraçōes sobre os achados clinicos e nęurológicos, em subgrupos etários. E ressaltada a malor frequencia da doença entre lactentes até 6 meses de idade.
\end{abstract}

Purulent meningitis in children during the first year of life.

SUMMARY - A series of 169 children with diagnosis of acute purulent meningitis during the first year of life was studied. Clinical and neurological findings are discussed, and for this purpose patients were separated in subgroups concerning their age. The great frequency in suckling until 6 months of age is emphasized.

A importância dos estudos das meningites bacterianas em crianças a partir dos primeiros dias de vida até um ano de idađe está ligada não só à elevada taxa de mortalidade, como à necessidade de identificar as várias alterações que incidem no sistema nervoso central (SNC), num período de rápido e conhecido desenvolvimento $\mathbf{2 , 3 , 1 6 , 1 7 , 2 1 , 3 0}$. Desde que, na criança normal, as funçōes neuropsicomotoras se evidenciam à medida em que sistemas e vias de associação se mielinizam, conjuntamente a outras condições maturativas, uma lesão cerebral que se instale durante os primeiros meses de vida tem provavelmente significado expectante e pior em relação àquelas que ocorrem nas idades mais avançadas $28-30$.

Com o objetivo de investigar aspectos qualitativos e quantitativos das manifestações neurológicas nas meningencefalites bacterianas agudas, estudamos um grupo de crianças de 0 a 1 ano de idade desde a admissão e durante a permanência hospitalar, para verificar o grau de comprometimento do SNC.

\section{MATERIAL F METODOS}

O material é constituido de 169 crianças com meningencefalites purulentas como doença primária, internadas no período de 1960 a 1975 nas enfermarias de Moléstías Infecciosas do Hospital das Clínicas da FMRP-USP, sendo o diagnóstico sempre confirmado pelo exame do liqilido cefalorraqueano (LCR). Foram excluidos todos os pacientes que, iuntamente com o processo meningencefalficico, apresentavam encefalopatia infantil, hidrocefalia, mal formaçăo raquimedurar, os casos de meningencefalites pós-cirurgia craniana ou perfuraçăo das meninges por instrumentos clrúrglcos, bem como aqueles com informacões clínicas e laboratoriaís nấo precisas. Das 169 pacientes, 69 eram do sexo feminino e 100 do masculino; a distribuiçăo dos casos nos diferentes grupos etários está assinalada na tabela 1 . Houve, no subgrupo etárío 0 a 6 meses de idade, 105 crianças e, entre 6 e 12 meses, 64.

Departamento de Neuronsiauiatria e Psicologia Médica, Faculdade de Medicina de Ribeirão Preto, Universidade de Săo Paulo (FMRP-USP): * Professor Adfunto. 


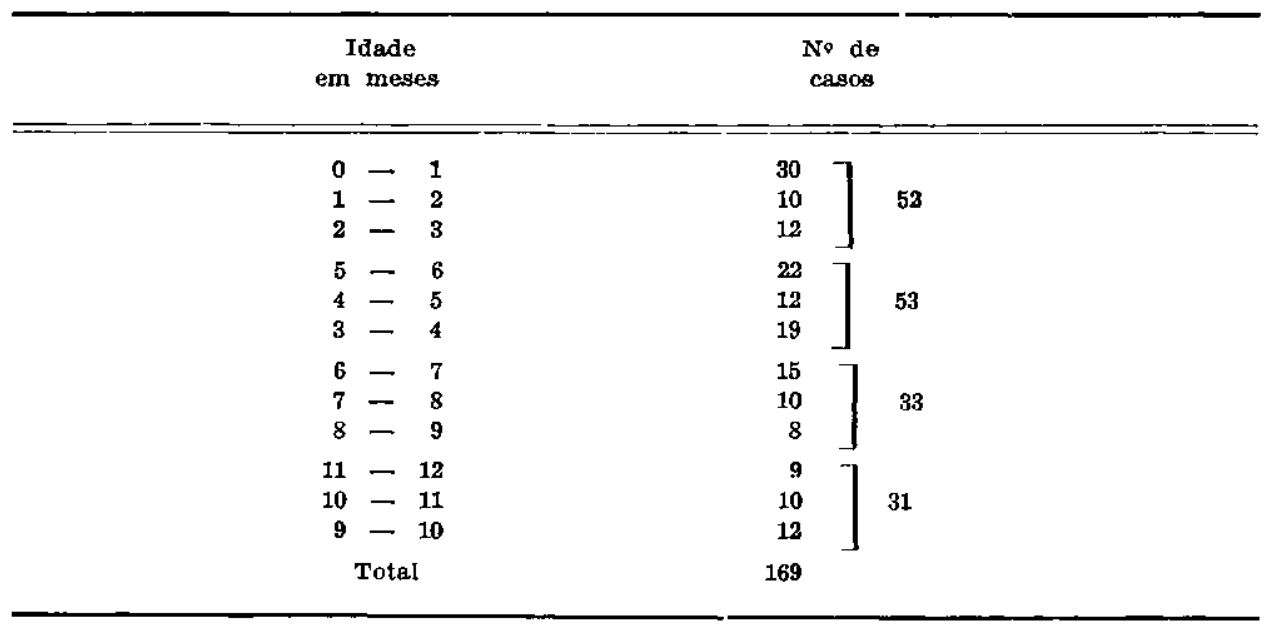

Tabela 1 - Distribuigão dos 169 pacientes por grupos etários.

Por casiăo da admissăo, na fase aguda da moléstia, os pacientes foram submetidos ao exame cllnico getal e neurológico, ao estudo do LCR, do eletrencefalograma (EEG) e outros exames subsidiários. Imediatamente após a colheita, eram realizados no LCR exames citológicos, bioquímicos e bacteriológicos. Admitimos o diagnóstico de meningencefalite purulenta somente naqueles pacientes que, ao lado dos achados clínicos, apresentavam no LCR alterações celulares e bioquimicas, conforme critérios estabelecidos em nosso meio 5,33, frente a normalidade, em crlancas 13,35. O tratamento esquematizado na fase aguda foi penicilina cristalina da dosagem $1000000 \mathrm{U}$ or $\mathrm{k} k / \mathrm{dia}$ administrada por via endovenosa, associada ao clorafenicol ( $80 \mathrm{mg} / \mathrm{Kg} / \mathrm{dia})$ e estreptomicina $(20 \mathrm{mg} / \mathrm{kg} / \mathrm{dia})$ por via intramuscular, ou usamos amplictina na dosagem de $400 \mathrm{mg} / \mathrm{kg} / \mathrm{dia}$, endovenosa e, posteriormente, por via intramuscular, essociada ou nẫo a kanamicina $(20 \mathrm{mg} / \mathrm{kg} /$ dia). Os medicamentos administrados por via endovenosa eram mantidos durante 7 dias; posteriormente, eram administrados por via intramuscular e, finalmente, em funço da evolucão favorável, por via oral. Todos os pacientes foram submetidos a hidratação endovenosa balanceada, para reparacâo das perdas agudas e manutençăo básica inferior hidroeletrolítica. A avaliação neurológica fol realizada duas vezes ao dia na fase aguda e os exames de LCR, repetidos semanalmente. A alta hospitalar foi deda após a normalizaçáo clínica e do LCR e. sempre que possivel, foi realizado EEG.

\section{RESULTADOS}

$\mathrm{Na}$ fase aguda, săo considerados os aspectos clínicos gerais da meningencefalite no recém-nascido (RN), em crianças com 1 a 3 meses de idade, com 3 a 6 meses, com 6 a 9 meses e com 9 a 12 meses.

Meningencefalite em neonatos - Foi diagnosticada entre o primeiro e o $28^{\circ}$ dia de vida em 30 neonatos, sendo 16 do sexo masculino e 14 do feminino. Na tabela 2 são apresentadas as condiçóes gestacionais, maternas, do parto propriamente dito e pôndero-estatural dos RN. Verificamos gestaçăo menor que 36 semanas em 10 mães, anormalidades gestacionais em 9. sofrimento fetal em 9, peso menor que $2500 \mathrm{~g}$ em 16 e estatura fgual ou inferior a $45 \mathrm{~cm}$ em 15. Na tabela 3 constam a época de inficio da doença: verificamos que ocorreu na primeira semana de vida em $18 \mathrm{RN}$, na segunda em 8 , na terceira em 3 e na quarta em 1 . Para o estudo dos sintomas e sinais clínicos e neurológicos catalogamos as avaliações médicas e as anotações sequienciais de enfermagem obedecendo os horários regłstrados nos prontuários 29. Observamos que febre, altenaçăo da vigílla, anormalidades respiratórias e convulsões foram freqüentes durante as primeiras 24 horas de doença. Hipotonia, alteraçỏes dos reflexos primitivos do RN e bregma tenso, com ou sem disjunçāo de suturas, foram detectados mals tandiamente. Anorexia, vômitos, tremores e criges de clanose ocorreram menos freqüentemente.

Meningencefalite em crianças com 1 a 12 meses de idade - Para uma melhor avaliaçăo comparativa dos sintomas e sinals clínicos e neurológicos, na fase aguda da doença, nos 


\begin{tabular}{|c|c|c|c|c|c|}
\hline Caso & $\begin{array}{c}\text { Tp Gestaça } \\
\text { (meses) }\end{array}$ & $\begin{array}{l}\text { Condiçōes } \\
\text { maternas }\end{array}$ & $\begin{array}{l}\text { Condições } \\
\text { do parto }\end{array}$ & $\begin{array}{c}\text { Peso } \\
(\mathrm{g})\end{array}$ & $\begin{array}{l}\text { Estatura } \\
\text { (cm) }\end{array}$ \\
\hline 1 & 9 & Normal & SF & 3920 & 51 \\
\hline 2 & 9 & Normal & $\mathbf{S F}$ & 4350 & 51 \\
\hline 3 & 9 & Endometrite e $\mathbf{F}$ & Normal & 3100 & 48 \\
\hline 4 & - & Convulsẫo & $\mathbf{S F}$ & 2500 & 44 \\
\hline $\mathbf{5}$ & 8 & Hiperemese e $F^{\prime}$ & Cesárea & 1600 & 45 \\
\hline 6 & 9 & Tuberculose & Normal & 1980 & 44 \\
\hline 7 & - & Normal & - & 3000 & - \\
\hline 8 & 9 & Anemia grave & Normal & - & - \\
\hline 9 & 8 & Pré-eclâmpsia & $\mathrm{SF}$ & 2100 & 43 \\
\hline 10 & 7 & Hipertensão arterial & Normal & 1710 & 44 \\
\hline 11 & 9 & Normal & Cesárea e sF & 2120 & 45 \\
\hline 12 & 8 & Normal & Normal & 一 & - \\
\hline 13 & 9 & Normal & Cesárea e SF & 1670 & 43 \\
\hline 14 & 8 & Normal & Pélvico & 1950 & 41 \\
\hline 15 & 8 & Idosa & Normal & 2360 & 46 \\
\hline 16 & 9 & Normal & Cesárea e SF & 2950 & - \\
\hline 17 & 8 & Normal & Normal & 2220 & 45 \\
\hline 18 & 8 & Normal & Cesárea & 3800 & 一 \\
\hline 19 & 8 & Normal & Normal & 2200 & 45 \\
\hline 20 & 9 & $\mathbf{M G}+$ & Fórcipe e SF & 2900 & 50 \\
\hline 21 & 9 & Normal & Normal & 3100 & 50 \\
\hline 22 & 9 & Normal & Normal & 2460 & 46 \\
\hline 23 & 9 & Normal & Cesárea & 2040 & 44 \\
\hline 24 & 9 & Normal & Normal & 2600 & 45 \\
\hline 25 & 9 & Normal & $2^{\circ}$ Gemelar SF & 2420 & 47 \\
\hline 26 & 9 & Normal & $2^{\circ}$ Gemelar & 2100 & 45 \\
\hline 27 & 8 & Normal & Normal & 2160 & 44 \\
\hline 28 & 9 & Normal & Normal & 3250 & 一 \\
\hline 29 & 9 & Normal & Normal & 2000 & 43 \\
\hline 30 & 9 & Normal & Normal & 4000 & 50 \\
\hline
\end{tabular}

Tabela 2 - Condicbes gestacionais, maternas e perinatais dos neonatos. Tp, tempo; $S F, 80 / r i-$ mento fetal; $F$, febre; $g$, gramas; $\mathrm{cm}$, centimetros; $M G+$, reacão de Machado Guerreiro positiva.

pacientes de 1 a 12 meses de idade, estudamos os subgrupos 1 a 3 meses (22 casos), 3 a 6 meses (53 casos), 6 a 9 meses (33 casos) e 9 a 12 meses (31 casos) (Tabela 4). Nos 22 pacientes com 1 a 3 meses de jdade fot constatado: febre em 19 (86,4\%) e ausência desso achado em 3: irritabilidade em 14 (63,6\%); vómitos em 13 (59\%); gemer contínuo ou fintermitente em 12 (54,5\%): fontanela bregmática abaulada em $11(50 \%)$; os demais sintomas e sinais ncorreram em menor freqijência. Nos 53 pacientes com 3 a 6 meses de idade, toi registrado: fehre em $50(94,3 \%)$ : irritabilidade em $41 \quad(77,3 \%)$ : vómitos em $34(64,1 \%)$; fontanela abaulada em 33 (62,3\%); normal em 15 e deprimida em 5; sinais de comprometimento meningeo em $29(54,7 \%)$; manifestações epilépticas em $22(41,5 \%)$; obnubilaçāo em 19 (35,8\%); os demais sintomas e sinais ocorreram em menor freqüência. Nos 33 pacientes com 6 a 9 meses de idade foi constatado: febre em 32 (96,9\%), que estava ausente em 1; sinais de comprometimento meníngeo em $23(69,7 \%)$; vômitos e irritabilidade em 19 (57,6\%); 1ontanela abaulada em $18(54,5 \%)$, normal em 6 e deprimida em 3i manifestacões epilepticas em 14 $(42,4 \%)$; os demais sintomas e sinais ocorreram em menor frequiência. Nos 31 pacientes com 9 a 12 meses de idade constatou-se: febre em 31 pacientes (100\%); vômitos em 24 (77,4\%); irritabilidade em 22 (71\%); sinais meníngeas em $19(61,3 \%)$; obnubilaçăo em 18 (58\%); fontanela abaulada em $16(51,6 \%)$, normal em 8 e deprimida em 3 ; crises epilépticas em 14 $(45,2 \%)$. 


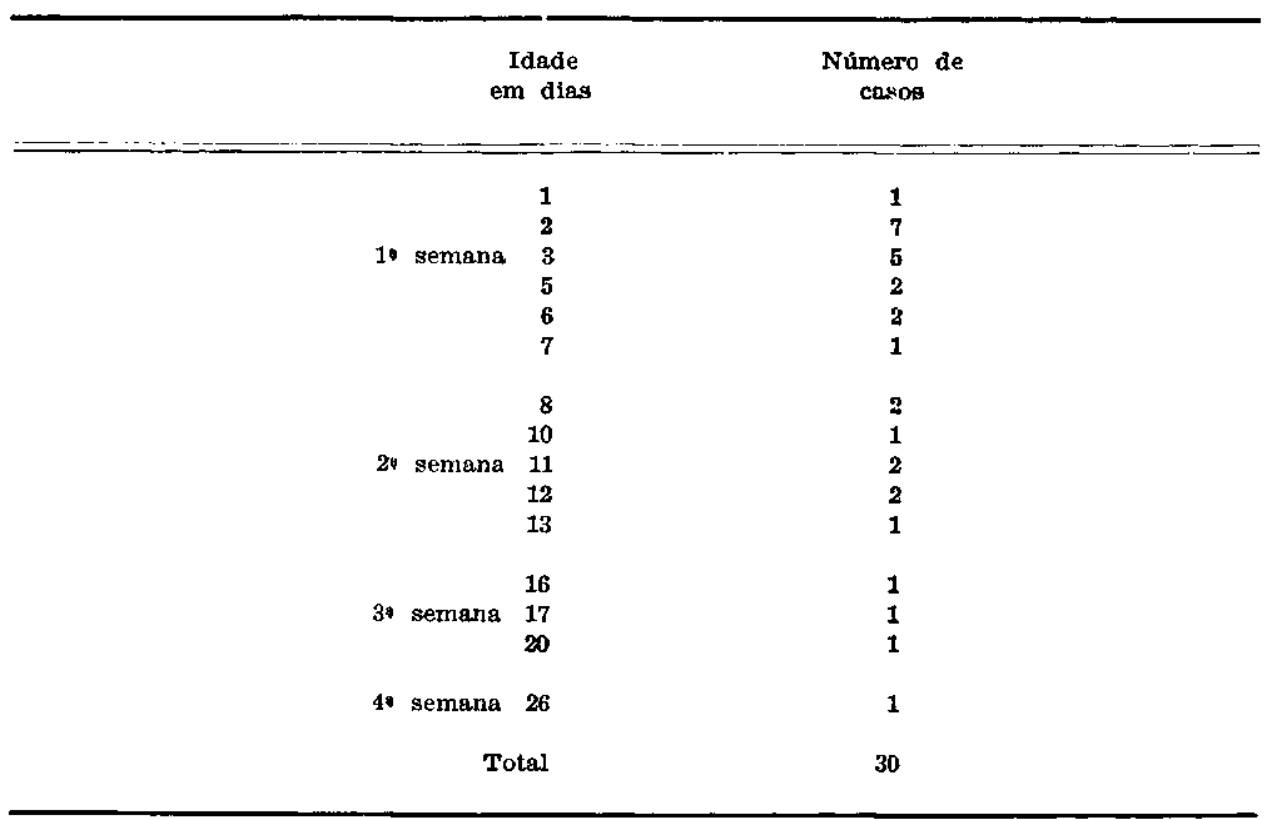

Tabela 3 - Epoca de inicio da doenga em $30 \mathrm{RN}$.

\begin{tabular}{|c|c|c|c|c|c|c|c|c|c|c|}
\hline \multirow[b]{2}{*}{$\begin{array}{l}\text { Sintomas e } \\
\text { Sinais Clínicos }\end{array}$} & \multicolumn{2}{|c|}{1 a 12 meses } & \multicolumn{2}{|c|}{1 a 3 meses } & \multicolumn{2}{|c|}{3 a 6 meses } & \multicolumn{2}{|c|}{6 a 9 meses } & \multicolumn{2}{|c|}{9 a 12 mesef } \\
\hline & $\begin{array}{l}\text { No de } \\
\text { casos }\end{array}$ & $\%$ & $\begin{array}{l}\text { INo de } \\
\text { casos }\end{array}$ & $\%$ & $\begin{array}{l}\text { No de } \\
\text { casos }\end{array}$ & $\%$ & $\begin{array}{l}\text { No de } \\
\text { casos }\end{array}$ & $\%$ & $\begin{array}{l}\text { No de } \\
\text { casos }\end{array}$ & $\%$ \\
\hline Febre & 132 & 95,0 & 19 & 86,4 & 50 & 94,3 & 32 & 96,9 & 31 & 100,0 \\
\hline Convulsðes & 58 & 41,7 & 8 & 36,3 & 22 & 41,5 & 14 & 42,4 & 14 & 45,2 \\
\hline Anorexia & 35 & 25,2 & 8 & 36,3 & 13 & 24,6 & 8 & 24,2 & 6 & 19,3 \\
\hline Palidez & 38 & 27,3 & $\mathbf{5}$ & 22,7 & 18 & 34,0 & 5 & 15,1 & 10 & 32,2 \\
\hline Vomitos & 90 & 64,7 & 13 & 59,0 & 34 & 64,1 & 19 & 57,6 & 24 & 77,4 \\
\hline Gemente & 42 & 30,2 & 12 & 54,5 & 16 & 30,2 & 8 & 24,2 & 6 & 19,3 \\
\hline Fontanela Abaulada & 78 & 56,1 & 11 & 50,0 & 33 & 62,3 & 18 & 54,5 & 16 & 51,6 \\
\hline Normal & 36 & 25,9 & 7 & 31,8 & 15 & 28,3 & 6 & 18,2 & 8 & 25,8 \\
\hline Deprimida & 15 & 10,8 & 4 & 18,2 & 5 & 9,4 & 3 & 9,1 & 3 & 9,7 \\
\hline Sinwais meningeos & 92 & 59,0 & 11 & 50,0 & 29 & 54,7 & 23 & 69,7 & 19 & 61,3 \\
\hline Irritabilidade & 96 & 69,0 & 14 & 63,6 & 41 & 77,3 & 19 & 57,6 & 22 & 71,0 \\
\hline Obnubilação & 57 & 41,0 & 8 & 36,4 & 19 & 35,8 & 12 & 36,4 & 18 & 58,1 \\
\hline Coms & 15 & 10,8 & 5 & 22,7 & 6 & 11,3 & 2 & 6,1 & 2 & 6,4 \\
\hline Nervos cranianos & 24 & 17,2 & $\mathbf{3}$ & 13,2 & 7 & 13,2 & 6 & 18,2 & 8 & 25,8 \\
\hline Faresia & 12 & 8,6 & 2 & 9,0 & 1 & 1,9 & 4 & 12,1 & $\mathbf{5}$ & 16,1 \\
\hline Petéquiss & 17 & 12,2 & 4 & 18,2 & 8 & 15,1 & 3 & 9,1 & 2 & 6,4 \\
\hline Total & 139 & & 22 & & 53 & & 33 & & $\mathbf{3 1}$ & \\
\hline
\end{tabular}


Na avaliação comparativa dos sintomas e sinais clínicos e neurológicos por ocasiño da admisaño a Hospital nos pacientes com 1 a 12 meses de idade observou-ge que: $\propto$ sômitos foram frequlentes no subgrupo 9 a 12 meses; os sinais de comprometimento mezíngeo (69,7\%), no subgrupo 6 a 9 meses; a fontanela estava normal ou deprimida com malor frequência no subgrupo 3 a 6 meses; a alteração da consciência e o comprometímento de nervos cranianos predominaram no subgrupo 9 a 12 meses.

\section{COMENTARIOS}

Nossa casuistica geral, demonstra que a doença predominou no sexo masculino e nos 6 primeiros meses de vida, com maior número de crianças no grupo etário de 3 a 6 meses.

MENINGENCEFALITES NO RECEM-NASCIDO -- No estudo dos 30 casos que tiveram a doença no periodo neonatal, constatamos predomínio na primeira e segunda semanas de vida. Foram admitidos através do ambulatório $9 \mathrm{RN}$, todos em estado grave (sobrevivência de apenas 2 casos); os demais (21) nasceram neste Hospital. $\mathrm{Na}$ análise das condiçōes gestacionais verificamos: tempo de gestação inferior a 36 semanas em 10 mães $(33,3 \%)$, sofrimento fetal em 9 RN $(30 \%)$, déficit ponderal em 16 crianças $(53,3 \%)$ e estatura igual ou inferior a $45 \mathrm{~cm}$ em $15(50 \%)$. As complicações obstétricas foram detectadas ao nascimento em 9 RN (30\%), cujos sintomas da moléstia surgiram precocemente, na primeira semana de vida. No grupo de início mais tardio, essas complicações não foram registradas. Esses dados valorizam as consideraçōes sobre os mecanismos de contaminação e infecção do RN durante o trabalho de parto, a partir de germes do aparelho gênito-urinário da mãe, particularmente nos RN dismaturos.

Em conseqüência dos mecanismos de defesa pouco desenvolvidos, com ausência ou baixo nivel de anticorpos protetores $4,9,15,18,25,31$ e da imaturidade da barreira hêmato-encefálica (BHE), o RN estaria predisposto as infecçóes, de tal modo que os sintomas podem surgir em curto espaço de tempo após o nascimento. Nos casos de início mais tardio, o microrganismo colonizado permanece assintomático e oportunamente, associado ou não a processo septicêmico, desenvolve agudamente a meningencefalite. As manifestações da doença na primeira semana, associadas a importantes alterações gestacionais e ao sofrimento fetal, induz ao estabelecimento de condutas que visam à proteção segura do $R N$ 8,12. No presente estudo, em 8 RN o quadro sintomatológico iniciou-se precocemente, no primeiro e segundo dias de vida; em 5 , de forma imbricada e não distinguível, de encefalopatia hipoxico-isquêmica neonatal. Nessa apreciação, às avaliações médica, repetidas a cada 3 horas, deparavam-se dificuldades no reconhecimento da meningencefalite bacteriana, instalada, a nosso ver, concomitantemente à anoxia perinatal. Além disso, a administração de antibióticos aos RN nascidos de partos complicados, benéficos e necessários em nosso entender, em doses nāo eficazes para infecções que comprometam o SNC, resultou em progressão sintomatológica nas horas subsequientes, com interferência relativa nos resultados do exame do LCR. Na presente série, o sofrimento fetal em 5 casos e a constatação de endometrite com febre no dia e no momento do parto constituiram situaçóes facilitadoras da infeç̧ão ao RN; dessa forma, a cultura do material vaginal estaria indicada visando à correlaçāo positiva com o agente etiológico detectado no LCR.

$\mathrm{Na}$ análise de nosso material pudemos verificar que os sintomas e sinais de meningite no periodo neonatal são semelhantes àqueles decorrentes das infecçōes bacterianas em geral, frequentemente estando ausentes os sinais especificos de comprometimento meningeo, melhor reconhecidos em lactentes e pré-escolares. $\mathrm{Na}$ fase aguda da moléstia nos RN predominaram a febre, as modificações do comportamento e vigilância, crises epilépticas e alteraçōes respiratórias. Assim, o choro ao manuseio, o gemer intermitente ou contínuo associado a manifestaçōes epilépticas atípicas, breves e mal definidas, bem como as modifícações respiratórias, com apnéias inesperadas, crises de cianose de reversão rápida, constituem elementos iniciais que poderão indicar envolvimento do SNC 29. Menos frequientemente pudemos observar os vômitos, a hipotonia, alterações nos reflexos primitivos e aumento da tensão da fontanela bregmática, nas primeiras 24 horas de doença. A distenção abdominal e a icterícia foram observadas em 7; aumento da glândula parótida em 3 e estrabismo convergente, em 2.

O quadro clínico, reconhecidamente grave porém pouco definido nas primeiras horas đa doença, não raramente conđuz aos diagnósticos de edema cerebral, broncopneumonia, septicemia e alterações cardíacas $1,7,10,14,29$. É importante considerar 
também a possibilidade da concomitância de afecções num mesmo RN; assim, a meningencefalite com broncopneumonia, foi diagnosticada em 8 de nossos pacientes. Os sinais neurológicos se tornam mais definidos nas horas subsequentes, havendo alteração progressiva do nível de vigilância, crises epilépticas bem definidas, hipotonia, alteraçăo dos reflexos arcaicos, palidez e tremores. Com relaçāo às modificaçōes térmicas, constatamos febre em RN a termo e peso adequado, ao passo que os de baixo pesc apresentavam temperatura normal ou mesmo hipotermia. Os tremores, sinais de colapso vascular e disjunção de suturas foram observados em casos com evolução desfavorável 11,25-27,29,34. A doença progrediu rapidamente ocorrendo o óbito 5 dias após 0 início dos sintomas, em 7 pacientes; progrediu de forma mais lenta, com óbito entre 7 e 22 dias, em 13; permaneceram vivos 10, um deles vindo a falecer acidentalmente durante transfusão de sangue.

MENINGENCEFALITE EM CRIANÇAS COM 1 A 12 MESES DE IDADE - De maneira global, verificamos que a incidência da febre, anorexia, irritabilidade, vômitos, abaulamentos da fontanela bregmática, sinais meningeos, manifestações epiléticas e obnubilação foi elevada na fase aguda. Subdividindo, os 139 pacientes de 1 a 12 meses em sub-grupos, observamos que a febre esteve presente em $100 \%$ dos casos de 9 a 12 meses e ausente em 7 com idade inferior a 9 meses (três tinham 2 meses de idade, sendo dois desnutridos de II grau; dois com 3 meses, um com 5 meses e um com 6 meses apresentavam também desnutrição de III grau). A obnubilação foi observada em $13(58,1 \%)$ de 9 a 12 meses, e, o estado de coma em $5(22,7 \%)$ dos pacientes de 1 a 3 meses de idade. Os vômitos foram mais freqüentes nos pacientes de 9 a 12 meses $(77,4 \%)$. A fontanela abaulada foi observada em $33(62,3 \%)$ de 3 a 6 meses e, normal ou deprimida em $11(50 \%)$ de 1 a 3 meses. As manifestaçōes epilépticas foram constatadas antes da admissāo hospitalar em 58 crianças $(41,7 \%)$ de 1 a 12 meses. A presença de hemiplegia foi observada predominantemente nos pacientes de 9 a 12 meses $(5$, ou $16,1 \%)$. O gemer contínuo ou intermitente apareceu em $54,5 \%$ de crianças de 1 a 3 meses. O comprometimento de nervos cranianos ocorreu em $25,8 \%$ dos casos de 9 a 12 meses.

A análise conjunta das manifestações clinicas, caracterizaram, portanto, a existência de comprometimento meningítico e encefalítico na fase aguda da moléstia porém, de maneira variável nos diferentes grupos etários considerados. A febre esteve ausente em 5\% dos pacientes, particularmente naqueles de idade mais precoce e que apresentavam simultaneamente desnutrição. Notamos ausência dos sinais meníngeos em $11(50 \%)$ pacientes de 1 a 3 meses, em $24(45,3 \%)$ de 3 a 6 meses, em $10(30,3 \%)$ de 6 a 9 meses em 12 pacientes $(38,7 \%)$ de 9 a 12 meses. Em 57 crianças, portanto, houve ausência dos sinais meníngeos, fato constatado também por outros autores 6,19,20,22-24. Dessa forma, entendemos que a inflamação das menínges, o edema perineural, a presença de germes e exsudatos na bainha das raizes nervosas explicariam a sintomatologia radicular. Entretanto, em lactentes este sinal pode estar ausente, ou presente com intensidade variável.

As manifestações epilépticas apareceram antes da admissão hospitalar em $41,7 \%$ das crianças e foram do tipo parcial ou generalizado, às vezes frustras, outras bem definidas pelos familiares e mesmo observadas pelo médico assistente. Foram interpretadas como alteração funcional ou mesmo lesional do SNC, sendo as causas: processo vascular encefálico, edema cerebral, hipertermia e alteração hidroeletrolitica ou, ainda, a associação de anormalidades. Dentre as 58 crianças que tiveram crises epilépticas antes da admissão hospitalar, 30 manifestaram crises parciais e, destas, em 16 houve suspeita de comprometimento vascular com paresia residual, denotando a gravidade da intercortência.

A fontanela bregmática quando aberta se mostrou abaulada em $56 \%$ e constituiu importante sinal para o diagnóstico. O fato de se apresentar normal ou deprimida em vários pacientes foi atribuido ao moderado grau de desidratação por ocasião da admissāo.

A gravidade sintomatológica por ocasião da internação, na maioria de nossas crianças, esteve relacionada não somente à idade e ao atraso no encaminhamento ao hospital como, ainda, à administração prévia de antibióticos em doses ineficientes. A partir dessas considerações e passando agora a valorizar os aspectos imunitários, as deficiências da $\mathrm{BHE}$ e aquelas ligadas aos mecanismos de maturação encefálica, verifica-se que as meningencefalites apresentam substrato patofisiológico suficiente para comprometer com maior ou menor gravidade as nobres estruturas cerebrais, alterando de maneira irreparável suas funções. Afirmamos pois, que o cérebro da criança 
de idade menor que um ano, agudamente atingido pelo processo infeccioso, poderá evidenciar contingente maior de lesōes encefalíticas reversiveis ou não. Nesse enfoque, a obnubilação, o coma, as crises convulsivas, as paresias e hemiplegias, o comprometimento de nervos cranianos devem ser valorizados e acompanhados, observando sua alteraçāo persistente ou normalização funcional durante o tempo de hospitalização. Se a vigilância médica mantida $\mathrm{e}$ as reconsiderações diagnósticas permitirem antever complicaçōes nesse grupo etário, devem elas ser ressaltadas, buscando logo a solução através de reavaliações laboratoriais e, sempre que indicado, por estudos ultrassonográficos ou de tomografia axial computadorizada.

No presente estudo, de 169 crianças, 44 (26\%) faleceram (20 pertenciam ao grupo dos RN). Constatamos 4 óbitos (18,2\%) no subgrupo 1 a 3 meses, 8 (15,0\%), $6(18,2 \%)$ e $6(19,4 \%)$, respectivamente nos sub-grupos 3 a 6 meses, 6 a 9 e 9 a 12 meses. Nossos resultados, assim considerados, são semelhantes aos de Sell 32 . E importante ressaltar que, em 5 casos, o óbito ocorreu dentro das primeiras 24 horas de doença, com evolução fulminante. Foi observado também que, em crianças de idade mais precoce, os pais nāo valorizaram suficientemente os sintomas, retardando a hospitalização.

\section{REFERENCIAS}

1. Barclay N - High frequency of Salmonella species as a cause of neonatal meningitis in Ibadan, Nigeria. Acta Paediat Scand 60:540, 1971.

2. Bastos CO, Taunay AE, Tiriba AC, Galvão PA, Sesso J, Fillipi J, Ballan N, Pupo AA, Godoy CVF - Meningites; consideraçōes gerais sobre 6957 casos internados no Hospital Emillo Ribas (SP). Rev Ass Méd Bras 16:27, 1970.

3. Bastos CO, Taunay AE, Galvão PA, Castro IO, Lomar AV - Meningites: consideraçס̄es gerais sobre 15067 casos internados no Hospital Emilio Ribas durante 1958-1972. Rev Ass M\$d Bras 19:451, 1974.

4. Bell WE, MaCormick WF - Bacterial meningitis: general concepts and management. In Neurologic Infections in Children. Saunders, Philadelphia, 1975.

5. Bittencourt JMT - Meningites de todas as etiologias. In Veronest $\mathbf{R}$ (ed): Doenças Infecclosas e Parasitárias. Ed. 3. Guanabara, Rio de Janeiro, 1964, pg 68.

a. Bresolin AU - Avaliaçño neurológiç e do lígijido cefalorraqueano em crianças com meningite meningocócica do soro grupo A. Arq Neuro-Psiquiat (São Paulo) 41:343, 1983.

7. Chevrie J, Aicardi J. Dhaussy C, Thieffry $\mathbf{S}$ - Les méningites purulentes du nouveau-né: étude de 36 cas. Arch $\mathrm{Fr}$ Pédiat 25:849, 1968.

8. Cussen L, Ryan GB - Hemorrhagic cerebral necrosis in infants with enterobacterial meningitis. J Pediat $71: 771,1967$.

9. Davies PA - Bacterial infection in the fetus and newborn. Arch Dis Childh 46:1, 1971.

10. Debry R, Mozziconaccl P, Berkman M - Les méningites purulentes au nouveau-né: étude clinique et pathogénique à propos de 13 cas. Sem Hôp Paris 30:4479, 1954.

11. Delaitre R, Testard R, Varlet $P$, Collin G, Achard J - Prognostic actuel des méningites purulentes du nouveau-né. Arch Fr Pédiat 26:559, 1969.

12. Diament AJ - Leptomeningites purulentas nos recém-nascidos. Pediat Prat (Såo Paulo) $35: 223,1964$.

13. Diniz HB - Determinaça da idade da criança em que o líquido cefalorraqueano atinge o padrăo de normalidade do adulto. Matern Inf (Såo Paulo) 16:291, 1957.

14. D'Oelsnitz $M$, Sansot $M$, Taramasco $H$ - Les méningites purulentes et neonatales: reflexions a propos de 10 observations. Arch Fr Pédiat 22:489, 1967.

15. Dyggve H - Prognosts in meningitis neonatorum. Acta Paediat (Stockholm) 51:303, 1962.

16. Etienne $M$, Curioni $S$, Laplane $\mathbf{R}$ - La gravité des méningites bactérlennes néonatales. Ann Pédiat (Paris) 12:421, 1965. 
17. Fiorillo AM Woiski JR, Moura-Ribeiro MV, Costa JC - Meningencefalites purulentas: achados clínicos e resultados terapeuticos em 50 casos. 19 Congresso Brasiledro de Neuroloxia. Ribeiråo Preto (SP), 1964.

18. Groover RV, Sutherlend JM, Landing BH - Purulent meningitis of newborn infants. N Fngl J Med 264:1115, 1969.

19. Haggerty RJ, Ziai $\mathbf{M}$ - Acute bacterial meningitis in children: controlled study of therapy with particular reference to combination of antibiotics. Pediatrics 25:742, 1960.

2). Jarv s CW, Saxena KM - Does prior antiblotic treatment hamper the diagnosis of acute bacterial meningitis? Clin Pediatr 11:201, 1972.

21. Jutitz $\mathrm{I}$ - Purulent meningitis in children with an analysis of death and CNS defects caused by it and its prognosis with antibiotic treatment. Arch Kinderh 181:40, 1970.

22. Lawson D, Metcalfe M, Pampiglione G - Meningitis in childhood. Br Med J 1:557, 1965.

23. Lefevre AB - Tratamento das meningites purulentas. Rev Paul Med 57:402, 1960.

24. Lefévre AB, Almeida IJM, Santos I, Elkis LC, Pazinato M Jr, Faredes MAN, Pinto MCB, Valente MI. Guimarăes MLO, Grosmann RM, Del Porto R, Gasal S, Cypel S, Groes SL - Estudo clínico de 78 casos de meninglte em criancas. Rev Bras Def Mental 10:109, 1975.

25. McCracken GH $\mathrm{Jr}$ - The rate of bacteriologic response to antimicrobial therapy in neonatal meningitis. Am J Dis Childh 123:547, 1972.

26. MeCracken GH Jr, Eichenwald HF - Leukocyte function and the development of obsonic and comolement activity in the neonate. Am J Dis Childh 121:120, 1971.

27. McDonald $R-$ Purulent meningitis in newborn babies. Clin Pediat 11:450, 1972.

28. Moura-Ribeiro MV - Meningencefalites purulentas em criancas: estudo clínico e eletrencefalográfico evolutivo. Tese de Doutoramento. Faculdade de Medicina de Ribeirăo Preto - USP. Ribeiråo Preto, 1971.

29. Moura-Ribeiro MV, Armbrust-Figueiredo J, Melo AN - Meningites bacterianas no recém-nascido: estudo de 20 casos. Arq Neuro-Psiquiat (Săo Paulo) 35:346, 1977.

30. Moura-Ribeiro MV, Wolski JR, Nobre MS, Fiorillo AM, Costa AC - Observacões sobre casos de meningoencefalitea purulentas tratadas com doses altas de antibióticos. III Congresso de Pediatria, Porto Alegre, 1964.

31. Muralt $G$ von - Importancia clínica del intercambio imunologico entre madre o hijo. In Ross A (ed): Imunologia Pediátrica. Edit Médico Pan-Americano, Buenos Aires, 1974, pg 33 .

32. Sell SHW - The clinical importance of $H$. Influenzae infection in children - Pediat Clin N Am 17:415, 1970 .

33. Spina-França A - Lquido cefalorraqueano. In Tolosa APM, Canelas HM (eds): Fropedeutica Neurológica. Procienx, Ș̄o Paulo, 1969.

34. Topczewski A, Melaragno Filho R, Cardim WH, Gomes MS, Mattosinho-França LC Meningite purulenta do recém-nasciło: estudo clínico e necroscópico de 11 casos. Clínica Peỏiatrica 1:7, 1982.

35. Woiski JR, Reis JB, Barrng HEV - Líqlildo cefalorraqueano do recém-nascido: conceito de normalidade. Arq Neuro-Psiquiat (São Paulo) 7:264, 1949. 